\title{
PUBLICIZAÇÃO DOS PLANOS MUNICIPAIS E INTERMUNICIPAIS DE RESÍDUOS SÓLIDOS DO ESTADO DE SÃO PAULO'
}

\author{
Ana Claudia Giannini Borges ${ }^{3}$ \\ Patricia Lopes Freire Pupin ${ }^{2}$ \\ Marcel Britto ${ }^{4}$
}

Resumo: A Política Nacional de Resíduos Sólidos - PNRS (Lei oํ 12.305/2010) estabelece a responsabilidade dos municípios quanto à elaboração, execução e publicização do Plano Municipal de Gestão Integrada de Resíduos Sólidos e/ou Plano Intermunicipal de Resíduos Sólidos. Assim, o objetivo é identificar e analisar o acesso aos referidos Planos Municipais do estado de São Paulo. Importa considerar que a Lei ํㅡ 12.527/2011 estabelece o acesso à informação pública como regra, bem como o Estatuto da Cidade (Lei no 10.257/2001) traz como diretriz a gestão democrática e participação da população na política urbana (incluindo os planos municipais). Após revisão bibliográfica e coleta de dados (sites, e-mail e ligação telefônica), identificou-se que há municípios que não apresentam as informações dos Planos nos órgãos competentes. Isto dificulta a publicização das informações em bancos de dados do governo, assim como o controle social estabelecido pela PNRS, logo, em franca violação das leis de regência.

Palavras-chave: Política nacional de resíduos sólidos; municípios; publicidade.

\section{PUBLICATION OF THE MUNICIPAL AND INTERMUNICIPAL SOLID WASTE PLANS OF THE STATE OF SÃO PAULO}

Abstract: The National Solid Waste Policy - PNRS in Portuguese acronym - (Law No. 12,305/2010), establishes the responsibility for municipalities to prepare, execute and publication a Municipal Integrated Management Plan for Solid Waste Management and/or an Intermunicipal Plan for Solid Waste. Thus, our objective is to identify and analyze the access to the Municipal Plans of the state of São Paulo. It is important to consider that the Law No. 12,527/2011 establishes the access to public information as a rule, and the City Statute (Law no. 10.257/2001), regulates the guideline for democratic management and public participation in urban policy (including municipal plans). After bibliographic review and data collection on sites, email, and telephone connection, it was findings show some municipalities do not present information related to the Plans in the competent bodies. This hinders the

\footnotetext{
${ }^{1}$ Trabalho realizado com apoio da FAPESP (Fundação de Amparo à Pesquisa do Estado de São Paulo) parte de um Projeto de Pesquisa Regular.

Mestranda em Geografia pela Universidade Estadual Paulista (UNESP) - Campus Rio Claro. patricialopesfreire@hotmail.com.

${ }^{3}$ Professora Assistente Doutora da Universidade Estadual Paulista (UNESP) - Campus Jaboticabal. acgiannini @ uol.com.br.

4 Doutorando pelo Programa de Pós-Graduação do Departamento de Ciências Ambientais (PPGCam) da UFSCar. marcelbritto@hotmail.com

Estudos Geográficos, Rio Claro, 16(2): 46-63, jul./dez. $2018 \quad$ (ISSN $\quad 1678-698 X)$ http://www.periodicos.rc.biblioteca.unesp.br/index.php/estgeo
} 
publicity of the information in government databases, as well as the social control established by the PNRS, thus, in clear violation of the laws of regency.

Keywords: National solid waste policy; counties; publicity.

\section{INTRODUÇÃO}

No Brasil, até a década de 1970, a questão ambiental não era uma prioridade para a política pública, porém passa a ser considerada como uma "estrutura independente", a partir de 1973, com as recomendações da Confederação das Nações Unidas sobre o meio ambiente (LUSTOSA, YOUNG, 2013). Os autores destacam que somente na década de 1980 foram estabelecidos os objetivos, ações e instrumentos da Política Nacional do Meio Ambiente, por meio da Lei no 6.938/1981 (BRASIL, 1981). Observa-se no Quadro 1, a seguir, que além desta política, a partir da década de 1980, há outras Leis e resoluções que são relevantes para a questão ambiental.

\section{Quadro 1 - Histórico da Política Ambiental, no Brasil, da década de 1980 até $2010^{5}$}

\begin{tabular}{|c|c|}
\hline 1981 & A Lei $n^{\circ} 6.938$ constituiu a Política Nacional do Meio Ambiente. \\
\hline 1986 & $\begin{array}{l}\text { A Resolução n 1/1986 do Conama menciona atividades como: o Estudo de Impacto Ambiental (EIA) e o } \\
\text { Relatório de Impacto Ambiental (Rima). }\end{array}$ \\
\hline 1988 & $\begin{array}{l}\text { Com a Constituição de 1988, as políticas ambientais no Brasil evoluíram e estados } \\
\text { e municípios passaram a ter competência para formular suas próprias políticas. }\end{array}$ \\
\hline 1989 & É criado o Instituto Brasileiro do Meio Ambiente e Recursos Naturais Renováveis (lbama). \\
\hline \multirow{2}{*}{1992} & Há a Conferência das Nações Unidas sobre Meio Ambiente e Desenvolvimento (RIO-92). \\
\hline & É criado o Ministério do Meio Ambiente para formular a Política de Meio Ambiente. \\
\hline 1996 & $\begin{array}{l}\text { São criados: a Política Nacional de Recursos Hídricos (Lei n 9.433); o Sistema Nacional de Gerenciamento } \\
\text { de Recursos Hídricos; e o Conselho Nacional de Recursos Hídricos. }\end{array}$ \\
\hline 1998 & $\begin{array}{l}\text { Condutas e atividades lesivas ao meio ambiente passam a sofrer sanções penais e administrativas } \\
\text { estabelecidas pela Lei } n^{\circ} 9.605 \text { - a Lei de Crimes Ambientais. }\end{array}$ \\
\hline \multirow{6}{*}{2000} & $\begin{array}{l}\text { A gestão ambiental vem a ser compartilhada entre os governos federal, estadual e municipal, com } \\
\text { transversalidade (a política ambiental entra na agenda dos diversos ministérios e órgãos públicos), controle } \\
\text { e participação social nas políticas ambientais. }\end{array}$ \\
\hline & $\begin{array}{l}\text { A gestão ambiental vem a ser compartilhada entre os governos federal, estadual e municipal, com } \\
\text { transversalidade (a política ambiental entra na agenda dos diversos ministérios e órgãos públicos), controle } \\
\text { e participação social nas políticas ambientais. }\end{array}$ \\
\hline & $\begin{array}{l}\text { Pela Lei n 9.984, tem-se: a Agência Nacional de Águas (ANA); a Política Nacional de Recursos Hídricos; e } \\
\text { o Sistema Nacional de Gerenciamento de Recursos Hídricos. }\end{array}$ \\
\hline & Promulgada a Lei n 9.974 que regulamenta sobre as Embalagens de Agrotóxicos. \\
\hline & A Lei n 9.966 rege sobre substâncias nocivas lançadas em águas sob jurisdição nacional. \\
\hline & A Lei n 9.985 institui o Sistema Nacional de Unidades de Conservação da Natureza. \\
\hline 2004 & É instituída a Lei n 10.881 , a qual dispõe sobre os contratos de gestão da ANA. \\
\hline 2006 & $\begin{array}{l}\text { São instituídas: a Lei n } 11.284 \text { (gestão de florestas públicas), criando o Fundo Nacional de } \\
\text { Desenvolvimento Florestal (FNDF) e o Serviço Florestal Brasileiro - SFB; e a Lei n } 11.428 \text { sobre a } \\
\text { utilização e proteção da vegetação nativa do bioma da Mata Atlântica. }\end{array}$ \\
\hline \multirow[b]{2}{*}{2007} & É criado o Instituto Chico Mendes de Conservação da Biodiversidade (Lei n 11.516/2007). \\
\hline & \begin{tabular}{|l} 
Promulgada a Lei $n^{\circ} 11.445$ que é conhecida como a Lei do Saneamento Básico. \\
É instituído o Plano Nacional de Mudança Climática (Decreto $\left.n^{\circ} 6.263\right)$. \\
\end{tabular} \\
\hline 2009 & Aprovação da Lei n 12.187, a Política Nacional de Mudanças Climáticas. \\
\hline \multirow{4}{*}{2010} & $\begin{array}{l}\text { É estabelecida a Política Nacional de Segurança de Barragens e também o Sistema Nacional de } \\
\text { Informações sobre Segurança de Barragens, ambos na Lei } n^{\circ} 12.334 .\end{array}$ \\
\hline & A Política Nacional de Resíduos Sólidos é instituída pela Lei n 12.305. \\
\hline & O Decreto $\mathrm{n}^{\circ} 7.404$ regulamenta a Lei $\mathrm{n}^{\circ} 12.305$ \\
\hline & $\begin{array}{l}\text { O Decreto n } 7.405 \text { institui o Programa Pró-Catador e o Comitê Interministerial para Inclusão Social e } \\
\text { Econômica dos Catadores de Materiais Reutilizáveis e Recicláveis. }\end{array}$ \\
\hline
\end{tabular}

Fonte: Elaborado a partir de Lustosa e Young (2013); Costa (2016) e Vieira e Cader (2013).

\footnotetext{
${ }^{5}$ Nota: A escolha pela data limite da pesquisa histórica, até o ano de 2010, se dá pelo foco principal de neste ano ser promulgada a Lei ${ }^{\circ} 12.305 / 2010$.

$\begin{array}{llllllll}\text { Estudos Geográficos, Rio } & \text { Claro, } & \text { 16(2): } & \text { 46-63, } & \text { jul./dez. } & 2018 & \text { (ISSN } & 1678-698 X)\end{array}$

http://www.periodicos.rc.biblioteca.unesp.br/index.php/estgeo
} 
Destaca-se em especial a Política Nacional de Resíduos Sólidos - PNRS (Lei no 12.305/2010) que é instituída após vinte e um anos de tramitação legislativa (BRASIL, 2012). Esta é um instrumento para orientar ações na área ambiental, a fim de obter um "desenvolvimento ambientalmente sustentável e socialmente justo". A PNRS estabelece a regulação legal sobre resíduos sólidos, definindo responsabilidades, diretrizes e regulamentações a serem cumpridas pelos setores público e privado.

Dentre as responsabilidades dos agentes, há para os municípios a exigência de elaboração, implementação e execução do Plano Municipal de Gestão Integrada de Resíduos Sólidos (PMGIRS) e/ou Plano Intermunicipal de Resíduos Sólidos (PIRS). Esta obrigatoriedade é para aqueles municípios com mais de 20.000 habitantes (e Distrito Federal). Os Planos devem conter a gestão dos resíduos sólidos (situação atual, ações futuras sobre os problemas identificados, entre outros), atendendo os dezenove incisos do art. 19 da Lei no 12.305/2010 (BRASIL, 2010a).

Esses Planos, conforme a PNRS, bem como pelo previsto nas Leis $\mathrm{n}^{\circ}$ 10.257/2001 (Estatuto da Cidade) e no 12.527/2011 (Acesso à informação) (BRASIL, 2011a), precisam estar publicizados. Tais leis, em especial a que garante acesso à informação está em consonância com a Constituição Federal que, no inciso XXXIII, do art. 5ํㅡㄹ confere o direito de toda população "receber dos órgãos públicos informações de seu interesse particular, ou de interesse coletivo ou geral, que serão prestadas no prazo da lei, sob pena de responsabilidade, ressalvadas aquelas cujo sigilo seja imprescindível à segurança da sociedade e do Estado" (BRASIL, 1988).

A Constituição Federal afirma ainda, no art. 37, que "a administração pública direta e indireta de qualquer dos Poderes da União, dos Estados, do Distrito Federal e dos Municípios obedecerá aos princípios de legalidade, impessoalidade, moralidade, publicidade e eficiência [...]" (BRASIL, 1988).

Pela Lei no 12.527/2011 é garantido o acesso à informação de dados públicos, tratando a publicidade como regra e o sigilo como exceção. Tal previsão está em conformidade com documentos internacionais, como: a Convenção das Nações Unidas contra a corrupção; o Pacto Internacional dos Direitos Civis e Políticos; e a Declaração Interamericana de Princípios de Liberdade de Expressão (BRASIL, 2011b). Essa Lei consolida o regime democrático do país, além de possibilitar que a sociedade participe das ações do Estado, bem como oportuniza maior controle social quanto a ações de corrupção (BRASIL, 2011b; STOERBEL, NOVELLI, 2013).

Assim, neste trabalho objetiva-se identificar e analisar 0 acesso aos PMGIRS e/ou PIRS dos municípios, do estado de São Paulo, que tem a obrigatoriedade de atender aos 19 incisos do art. 19 da Lei $n \equiv$ 12.305/2010. Como objetivos específicos têm-se: identificar a existência desses Planos Municipais; e verificar o processo de obtenção dos Planos e das leis que os institui.

\section{LEGISLAÇÃO E FUNDAMENTAÇÃO TEÓRICA}

A Política Nacional de Resíduos Sólidos (PNRS), Lei nำ 12.305/2010 (BRASIL, 2010a), envolve todos os entes federados, a sociedade e o setor produtivo (agropecuário, serviços, construção civil e indústria) para a resolução de problemas que afetam a qualidade de vida, neste caso em específico aos relacionados à "gestão ambientalmente correta dos resíduos sólidos". Brasil (2012, p. 2) destaca que na PNRS são definidas as responsabilidades de cada parte, sendo que: o cidadão deve dispor adequadamente dos resíduos sólidos, bem como repensar e

Estudos Geográficos, Rio Claro, 16(2): 46-63, jul./dez. $2018 \quad$ (ISSN 1678 -698X) http://www.periodicos.rc.biblioteca.unesp.br/index.php/estgeo 
rever o seu padrão de consumo; o setor privado produtivo deve gerenciar os resíduos gerados em sua atividade, com a "reincorporação na cadeia produtiva" e proposição de inovações; e os entes federados (federal, estadual e municipal, assim como o Distrito Federal) devem elaborar e implementar os Planos de Gestão de Resíduos Sólidos, de âmbito municipal ou intermunicipal.

A PNRS é regulamentada pelo Decreto n 7.404/2010 (BRASIL, 2010b) que traz a determinação do processo de construção dos Planos de Resíduos Sólidos, em específico no art. 50, abordando os planos municipais de gestão integrada de resíduos sólidos. Tais planos devem seguir o definido no art. 19 da Lei $\mathrm{n}^{\circ}$ 12.305/2010, que impõe como conteúdo mínimo o previsto nos 19 incisos do mesmo artigo, obrigatoriamente (BRASIL, 2010a). No Decreto, ressalta-se que os municípios com menos de 20.000 habitantes podem elaborar Planos Municipais simplificados. Esta condição não cabe para aqueles municípios que:

\section{I - integrantes de áreas de especial interesse turístico; \\ II - inseridos na área de influência de empreendimentos ou atividades com significativo impacto ambiental de âmbito regional ou nacional; ou \\ III - cujo território abranja, total ou parcialmente, unidades de conservação (BRASIL, 2010b, art. 51, § 2º).}

Este Decreto estabelece que com a elaboração do plano de resíduos sólidos é possível ter "acesso a recursos da União ou por ela controlados, bem como para que sejam beneficiados por incentivos ou financiamentos de entidades federais de crédito ou fomento [...]" (BRASIL, 2010b, art. 78), destinados à limpeza urbana, ao manejo e à gestão de resíduos sólidos. Esta concessão de crédito fica atrelada a comprovação de regularidade fiscal do ente federado. Ainda pelo mesmo Decreto, a prioridade para a concessão de crédito, no caso dos municípios, será para aqueles que: optarem por propostas consorciadas intermunicipais de gestão de resíduos sólidos; estejam inseridos em planos microrregionais de resíduos sólidos; e tenham coleta seletiva, com atuação de cooperativas/associações de catadores de materiais reutilizáveis e recicláveis (BRASIL, 2010b, art. 79).

O Decreto no 7.404/2010 institui, também, o Sistema Nacional de Informações sobre gestão dos Resíduos Sólidos - SINIR, um dos instrumentos da PNRS, que está vinculado ao Ministério do Meio Ambiente (BRASIL, 2010b, art. 71). Este sistema tem como finalidade, dentre outras, coletar, sistematizar, armazenar, compartilhar, disseminar os dados e informações sobre o gerenciamento e a gestão de resíduos sólidos, inclusive sobre os municípios. Este Sistema também está atrelado ao Sistema Nacional de Informações sobre Meio Ambiente (SINIMA) e ao Sistema Nacional de Informações sobre Saneamento (SNIS), respectivamente, coordenados pelo Ministério do Meio Ambiente e Ministério das Cidades.

Na PNRS tem-se um princípio que trata da divulgação, ao estabelecer "o direito da sociedade à informação e ao controle social" (BRASIL, 2010a, art. 6ํ, inciso X). Além de afirmar que "é assegurada ampla publicidade ao conteúdo dos planos de resíduos sólidos, bem como controle social em sua formulação, implementação e operacionalização" (BRASIL, 2010a, art. 14, Parágrafo Único). Assim, pode-se considerar que a divulgação dos Planos municipais individuais e consorciados deve ser realizada. Contribuindo para tal obrigatoriedade, tem-se a Lei nํ 12.527 de 2011 que regula o acesso de dados e informações públicas (BRASIL, 1988, art. 5ํㅜㄴ, inciso XXXIII, e art. 37; BRASIL, 2011a). Ademais, o Estatuto da Cidade (Lei no 10.257/2001) ao regulamentar a política urbana prevista na

Estudos Geográficos, Rio Claro, 16(2): 46-63, jul./dez. $2018 \quad$ (ISSN 1678 -698X) http://www.periodicos.rc.biblioteca.unesp.br/index.php/estgeo 
Constituição (Arts. 182 e 183), consagra o princípio de "gestão democrática por meio da participação da população e de associações representativas dos vários segmentos da comunidade na formulação, execução e acompanhamento de planos, programas e projetos de desenvolvimento urbano" (BRASIL, 2017), o que, a seu turno impõe amplo acesso e divulgação das informações.

Sobre 0 acesso às informações e sobre sua divulgação, a Lei $n^{\circ}$ 12.527/2011, dispõe:

Art. 8o É dever dos órgãos e entidades públicas promover, independentemente de requerimentos, a divulgação em local de fácil acesso, no âmbito de suas competências, de informações de interesse coletivo ou geral por eles produzidas ou custodiadas.

$\S 1^{\circ} \mathrm{Na}$ divulgação das informações a que se refere o caput, deverão constar, no mínimo:

$[\ldots]$

V - dados gerais para o acompanhamento de programas, ações, projetos e obras de órgãos e entidades (BRASIL, 2011a).

Nesta mesma Lei, tem-se que a disponibilização das informações, pelos órgãos e entidades públicas, deve ser por "meios e instrumentos legítimos de que dispuserem", tendo que necessariamente ocorrer em sítios oficiais (internet). Estes sítios devem atender as especificações do art. 8ํㅗ $§ 3^{\circ}$ :

I - conter ferramenta de pesquisa de conteúdo que permita o acesso à informação de forma objetiva, transparente, clara e em linguagem de fácil compreensão;

II - possibilitar a gravação de relatórios em diversos formatos eletrônicos, inclusive abertos e não proprietários, tais como planilhas e texto, de modo a facilitar a análise das informações;

III - possibilitar o acesso automatizado por sistemas externos em formatos abertos, estruturados e legíveis por máquina;

IV - divulgar em detalhes os formatos utilizados para estruturação da informação;

V - garantir a autenticidade e a integridade das informações disponíveis para acesso;

VI - manter atualizadas as informações disponíveis para acesso;

VII - indicar local e instruções que permitam ao interessado comunicar-se, por via eletrônica ou telefônica, com o órgão ou entidade detentora do sítio; e

VIII - adotar as medidas necessárias para garantir a acessibilidade de conteúdo para pessoas com deficiência (BRASIL, 2011).

É importante considerar que esta obrigatoriedade é para municípios com mais de 10.000 habitantes, exceto para as informações financeiras e orçamentarias que devem ser disponibilizadas por todos os municípios em atendimento a Lei de Responsabilidade Fiscal.

Stoeberl e Novelli (2013) e Oliveira (2013), sobre a Lei oㅜ 12.527/2011, ressaltam que esta legislação deve ser cumprida e quando necessário faz-se impreterível a atuação do Poder Judiciário, garantindo o direito de todos, como determinado na própria Lei. Os autores ressaltam que o direito à informação também é uma necessidade humana e esta deve ser clara, objetiva, transparente e de simples linguagem, conforme rege a Lei. Tais condições devem ser atendidas para

Estudos Geográficos, Rio Claro, 16(2): 46-63, jul./dez. $2018 \quad$ (ISSN $\quad$ 1678-698X) http://www.periodicos.rc.biblioteca.unesp.br/index.php/estgeo 
que se propicie o acesso fácil, independentemente do grau de instrução da pessoa (OLIVEIRA, 2013), garantindo assim uma condição efetivamente democrática.

Quanto ao fato do acesso à informação ser um direito fundamental, isto está apresentado em diferentes documentos de órgãos internacionais, ou seja, em diplomas internacionais (BRASIL, 2011b; OLIVEIRA, 2013). A declaração Universal dos Direitos Humanos, de 1948, em seu art. 19 define que "todo o indivíduo tem direito à liberdade de opinião e de expressão, o que implica o direito de não ser inquietado pelas suas opiniões e o de procurar, receber e difundir, sem consideração de fronteiras, informações e ideias por qualquer meio de expressão." (ONU, 2009). Pelo disposto no art. 10 da Convenção das Nações Unidas contra a corrupção, de 2003, tem-se que todo o Estado, objetivando combater a corrupção.

[...] em conformidade com os princípios fundamentais de sua legislação interna, adotará medidas que sejam necessárias para aumentar a transparência em sua administração pública, inclusive no relativo a sua organização, funcionamento e processos de adoção de decisões, quando proceder (ONU, 2007).

Este mesmo documento, ao tratar da participação da sociedade, estabelece em seu art. 13 que o Estado deve "garantir o acesso eficaz do público à informação" (ONU, 2007), logo, a transparência das informações tem, dentre outras, a finalidade de combater a corrupção. O sistema de controle social propiciado pelo acesso à informação, segundo Oliveira (2013) e Stoeberl e Novelli (2013), além de prevenir a corrupção, fortalece a cidadania e consolida a democracia.

Outro documento internacional que trata sobre o tema é a Declaração Interamericana de princípios de Liberdade e Expressão, de 2000. Nos princípios (item 4), deste documento, está estabelecido que "o acesso à informação em poder do Estado é um direito fundamental do indivíduo. Os Estados estão obrigados a garantir o exercício desse direito." (OEA, 2000). E, por fim, tem-se o Pacto Internacional dos Direitos Civis e Políticos, de 1976 que, em seu art. 19 estabelece:

Toda a pessoa tem direito à liberdade de expressão; este direito compreende a liberdade de procurar, receber e divulgar informações e ideias de toda a índole sem consideração de fronteiras, seja oralmente, por escrito, de forma impressa ou artística, ou por qualquer outro processo que escolher (ONU, 1976).

A Agenda 21, adotada pelas Nações Unidas quando da realização da Conferência sobre Ambiente e Desenvolvimento no Rio de Janeiro em 1992, estabelece como requisito ao desenvolvimento sustentável a ampla participação pública nos processos decisórios. Assim também a Convenção sobre o Acesso à Informação, Participação do Público no Processo de Tomada de Decisão e Acesso à Justiça em Matéria Ambiental, assinada em Aarhus, na Dinamarca, em 25 de junho de 1998, preconiza o direito de informação de maneira ampla e irrestrita (OLIVEIRA et al, 2016)

Ademais, a Declaração de Atlanta e plano de ação para o avanço do direito de acesso à informação, de 2008, conclama a comunidade internacional a criar, desenvolver e alimentar o direito de acesso a informação como expressão de direito fundamental (INTERNACIONAL CONFERENCE ON THE RIGHT PUBLIC INFORMATION, 2008).

Estudos Geográficos, $\quad$ Rio $\quad$ Claro, $\quad 16(2): \quad 46-63, \quad$ jul./dez. $2018 \quad$ (ISSN 1678 -698X) http://www.periodicos.rc.biblioteca.unesp.br/index.php/estgeo 
Pelo constante nestes documentos internacionais, é possível reafirmar a importância que deve ser dada ao acesso à informação, em específico às públicas. Oliveira (2013) e Stoeberl e Novelli (2013) destacam que, com a Lei no 12.527/2011, o acesso à informação passa a ser regra e o sigilo, exceção. E esta última ocorre quando estiver relacionada às questões de segurança nacional e de Estado (soberania, relações internacionais e atividades de inteligência).

Oliveira (2013, p. 22) aponta que a publicidade realizada pelo Estado pode ser categorizada de duas formas: transparência ativa que "consiste no dever da Administração Pública (Estado) de divulgar informações à sociedade sponte propria (por iniciativa própria)"; e transparência passiva em que o "Estado presta acesso à informação sob demanda em atendimento às solicitações da sociedade". O autor destaca que, segundo a Lei, "as informações de interesse coletivo ou geral" que foram geradas em órgãos públicos devem ser divulgadas sem uma demanda (requerimento). Assim, as informações sobre resíduos sólidos, como definido pela PNRS e no Decreto no 7.404/2010 (art. 12, parágrafo único), podem ser categorizadas como transparência ativa, visto que todos os entes da federação, nos três níveis de governo, devem disponibilizar as informações sobre resíduos sólidos, "sob sua esfera de competência" (BRASIL, 2010a).

Deste modo, observa-se que há o estabelecimento de um ambiente mais "transparente", em que o controle social é prestigiado tanto pela PNRS como pela implementação da Lei no $12.527 / 2011$, fortalecendo, desta forma, a cidadania e a democracia (OLIVEIRA, 2013). Esta legislação viabiliza ao cidadão uma atuação mais ativa na sociedade, podendo "monitorar" e "fiscalizar" a gestão pública, inclusive quanto à gestão dos resíduos sólidos nos municípios.

Retomando fundamental questão feita por Arnstein em 1969 (2002, p.1): “o que é participação cidadã e qual a sua relação com os imperativos sociais de nosso tempo?", a autora elabora níveis, em forma de escada, úteis na compreensão da questão da participação (sendo os números mais baixos os correspondentes aos degraus mais baixos e, portanto, menos participativos/democráticos), como visível:

\section{Quadro 2 - Oito degraus da escada da participação-cidadã de Arnstein}

\begin{tabular}{|ll|}
\hline 8 Controle Cidadão & Níveis de poder cidadão \\
7 Delegação de Poder & Níveis de poder cidadão \\
6 Parceria & Níveis de poder cidadão \\
5 Pacificação & Níveis de concessão mínima de poder \\
4 Consulta & Níveis de concessão mínima de poder \\
3 Informação & Níveis de concessão mínima de poder \\
2 Terapia & Não-participação \\
1 Manipulação & Não-participação \\
\hline Fonte: ARNSTEIN (2002, p.2). &
\end{tabular}

Desse modo, quando o Estado (incluindo todas as esferas, como no caso em estudo: os municípios) falha ao conceder informação ao povo, insubsistente qualquer discurso de legitimação das políticas públicas, observa-se o esvaziamento de qualquer fundamento democrático.

$\mathrm{Na}$ etimologia, transparente é aquilo que se deixa atravessar pela luz (CUNHA, 2000, p. 783), assim, o sentido de transparência evoluiu para a circunstância em que os cidadãos enxergam através da administração. Ademais,

Estudos Geográficos, Rio $\quad$ Claro, $\quad$ 16(2): 46-63, jul./dez. $2018 \quad$ (ISSN 1678 -698X) http://www.periodicos.rc.biblioteca.unesp.br/index.php/estgeo 
sobreleva a importância da transparência no contexto em que se deve ter políticas públicas participativas, haja vista que a publicidade e a informação são suas bases.

Nesse contexto, a Lei de Acesso à Informação, ao prever a máxima divulgação de dados por todos os órgãos e esferas do Poder Público, exige sua aplicação integral. Como forma de garantir acesso à informação e à publicização, importa distinguir entre a transparência ativa e e passiva. $(\mathrm{HOCH}$; RIGUI; SILVA, 2013; OLIVEIRA, 2013)

Portanto, há complementariedade entre os dispositivos constitucionais - art. $5^{\circ}$, XXXIII, art. 37, 182 etc (BRASIL, 1988) e legais, notadamente pela Lei de Acesso à Informação (BRASIL, 2011).

Fato é que toda e qualquer política pública deve ser orientada para a participação popular efetiva (na efetivação de uma democracia direta) como forma de promover o bem comum - objetivo do Estado como expresso no art. $3^{\circ}$ da Constituição da República Federativa do Brasil de 1988. A inefetividade dos comandos de publicidade e acesso à informação consiste em óbice à cidadania $e$ grave descumprimento de como devem ser (todas) as políticas públicas.

\section{METODOLOGIA}

Para a realização deste trabalho, fez-se revisão bibliográfica sobre resíduos sólidos e acesso à informação, a partir de legislação, estudos e artigos. Para a coleta de dados, consideraram-se os municípios que possuem mais de 20.000 habitantes, no Censo Demográfico (IBGE, 2010), sendo 250 municípios dos 645 municípios do estado de São Paulo. Estes estão distribuídos nas quinze mesorregiões do Estado. Não foram considerados os municípios com menos de 20.000 habitantes que podem elaborar Planos Municipais simplificados.

A primeira coleta foi realizada no sítio do Sistema Nacional de Informações sobre gestão dos Resíduos Sólidos - SINIR (BRASIL, 2018a), especificamente, nos Planos Municipais de Gestão Integrada de Resíduos Sólidos. Nesta base, apresentam-se dados da Pesquisa de Informações Básicas Municipais - MUNIC do IBGE (2014) e do Ministério do Meio Ambiente. Os dados referem-se aos anos de 2013 e 2015 e apresentam a quantidade de municípios que possuem ou não PMGIRS, por mesorregião.

Fez-se também coleta na base de dados auto declaratória do Sistema de Informações em Saneamento (SNIS), especificamente para resíduos sólidos (SNISRS). Neste foi consultado o Diagnóstico do Manejo de Resíduos Sólidos Urbanos de 2016 (BRASIL, 2018b), de modo específico à planilha denominada "Políticas, planos e consórcios 2016", em que se identifica se o município tem PMGIRS ou PIRS.

Para identificar se os municípios possuem os PMGIRS ou PIRS, as Leis que os instituíram e como estes são publicizados, foi utilizado outro método. Realizou-se coleta de dados em sítios oficiais do Estado e dos municípios, bem como por contato telefônico e e-mail aos órgãos competentes nos municípios. Esta busca perdurou por sete meses e possibilitou também o acesso aos Planos Municipais e as Leis (Leis ordinárias/extraordinárias ou Decreto) que os institui.

Utilizou-se como recorte metodológico a análise dos Planos instituídos como PMGIRS ou até Consórcios (PIRS) que contemplem apenas o manejo de resíduos sólidos, excluindo os que se encontram anexados e instituídos como parte do Plano Municipal de Saneamento Básico.

Estudos Geográficos, $\quad$ Rio $\quad$ Claro, $\quad 16(2): \quad 46-63, \quad$ jul./dez. $2018 \quad$ (ISSN 1678 -698X) 


\section{RESULTADOS E DISCUSSÃO}

Ao analisar o acesso à informação dos PMGIRS e/ou PIRS pode-se considerar primeiro o Sistema Nacional de Informações sobre gestão dos Resíduos Sólidos SINIR, visto que este é o instrumento principal definido na PNRS (BRASIL, 2010a).

Informação pode definir-se como a consciência sobre factos ou dados, pressupondo esforço (intelectual) que permita passar da informação imanente (dos factos ou dados brutos) à sua percepção e entendimento, implicando na recolha, tratamento e organização dos dados. (GONÇALVES, 2003, p. 17). Assim, a publicização (oferta facilitada) dos dados é a primeira exigência à informação - ambos, deveres constitucionais e legais do Estado (e direito dos cidadãos).

Neste Sistema há vários passos até obter a informação desejada. É possível verificar a identificação para Planos de Resíduos Sólidos (aba), nesta são apresentados os direcionamentos para planos (outras abas): nacional; estadual; microrregional, metropolitana ou de aglomeração; intermunicipal; municipal; e de gerenciamento. Especificamente na parte para os Planos Intermunicipais há explicação sobre as dificuldades da gestão de Resíduos Sólidos, a importância dos consórcios, as características desses Planos, porém não há a apresentação de dados (BRASIL, 2018a). Na parte sobre Planos Municipais, há uma explicação sobre estes e a apresentação de dados que permitem identificar os municípios que possuem ou não PMGIRS (FIGURA 1).

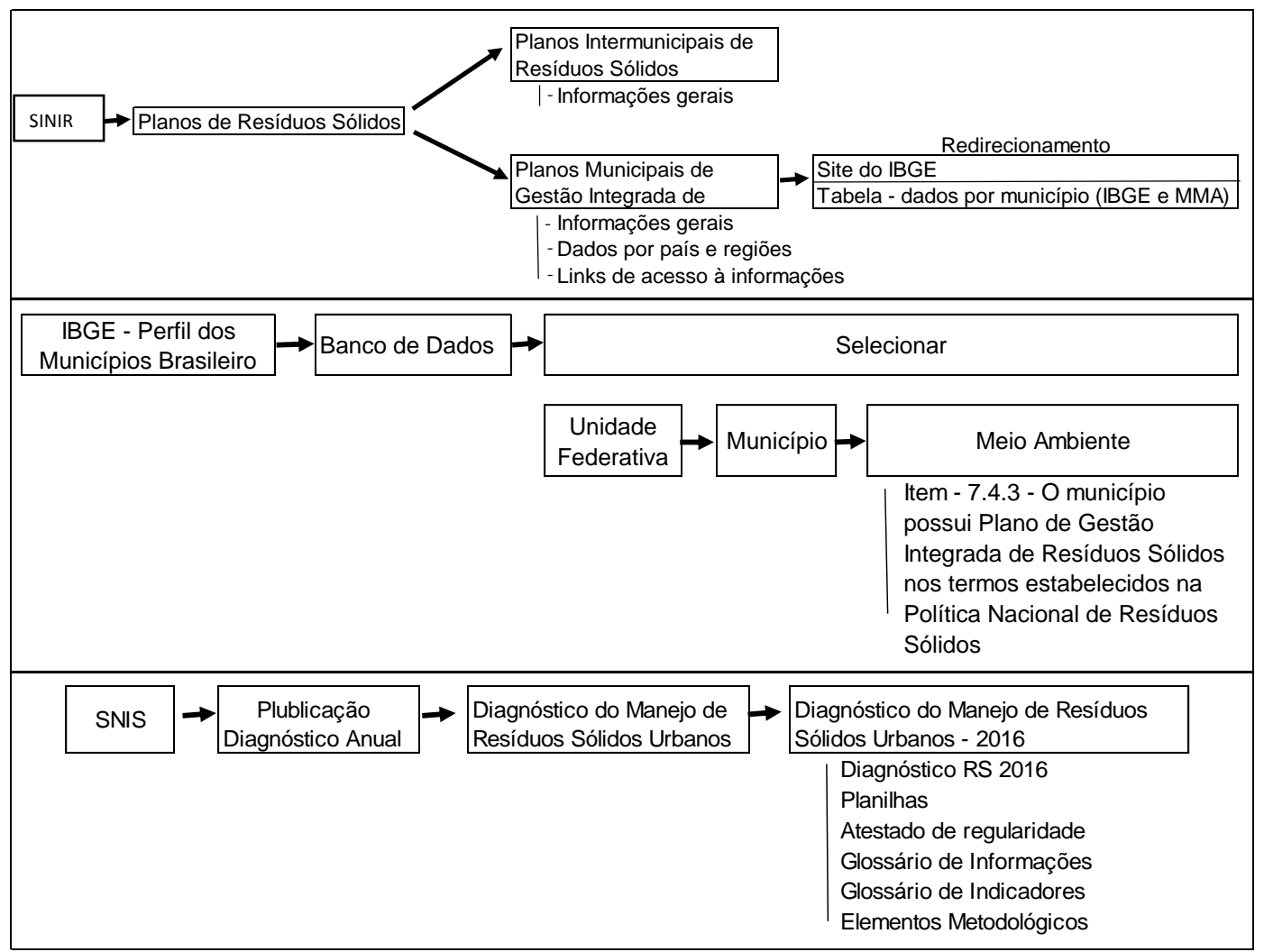

Figura 1 - Processo de acesso a Informações sobre PMIGRS e PIRS, na base do SINIR, MUNIC/IBGE e SNIS.

Fonte: SINIR (BRASIL, 2018a), IBGE (2014) e SNIS-RS (BRASIL, 2018b).

Estas informações são obtidas por redirecionamento para: a página do IBGE, especificamente para Pesquisa de Informações Básicas Municipais - MUNIC (IBGE, 2014); e uma planilha com dados de todos os municípios do país para 2013 Estudos Geográficos, Rio Claro, 16(2): 46-63, jul./dez. $2018 \quad$ (ISSN 1678-698X) http://www.periodicos.rc.biblioteca.unesp.br/index.php/estgeo 
(dados compilados de MUNIC/IBGE) e de uma pesquisa realizada pelo Ministério do Meio Ambiente (MMA) para o ano de 2015 (BRASIL, 2018a). É importante considerar que são várias as informações contidas na planilha, o que exige conhecimento mínimo para obtê-las. O acesso à base do IBGE, também, exige conhecimento mínimo, visto que são vários os passos para a obtenção do dado, para cada município, no tema Meio Ambiente, item 7.4.3 (FIGURA 1).

Outra forma de obter informações sobre os Planos Municipais é consultando - Sistema Nacional de Informações sobre Saneamento (SNIS), do Ministério das Cidades (BRASIL, 2018b). Para tal, é preciso passar por vários redirecionamentos até obter o último Diagnóstico do Manejo de Resíduos Sólidos Urbanos (ano de 2016). Este apresenta vários arquivos, tais como Diagnóstico, Planilhas, Glossários, dentre outros (FIGURA 1). A informação sobre a existência ou não de PMGIRS ou PIRS nos municípios está disponível no arquivo denominado "Planilhas", especificamente em "Planilha_Politicas_Planos_Consorcios_2016".

É importante considerar que para obter estas informações é preciso saber que estas estão disponibilizadas nesses sítios (SINIS, IBGE e SNIS-RS), o que não é de amplo conhecimento. Para acessar os dados, tentativas e conhecimento mínimo sobre o tema e esses sítios são necessários. Estas dificuldades são um descumprimento ao indicado na Lei $\mathrm{n}^{\circ}$ 12.527/2011, visto que as informações deveriam ser facilmente obtidas, independentemente do nível de instrução e conhecimento das pessoas, como destacado por Oliveira (2013).

A partir destas buscas, considerando aqueles municípios que obrigatoriamente devem ter PMGIRS, pôde-se identificar a informação da existência ("sim") ou "não" dos Planos para os municípios, por mesorregião (TABELA 1).

\section{Tabela 1 - Existência de PMGIRS e PIRS nas 15 mesorregiões do estado de São}

\section{Paulo}

\begin{tabular}{|c|c|c|c|c|c|c|c|c|c|}
\hline \multirow{3}{*}{ Mesorregiões } & \multirow{3}{*}{$\begin{array}{l}\text { Municípios } \\
\text { (Número) }\end{array}$} & \multicolumn{2}{|c|}{ Base IBGE/SINIR } & \multirow{2}{*}{\multicolumn{2}{|c|}{$\begin{array}{c}\text { Base MMA/SINIR } \\
\text { PMGIRS }\end{array}$}} & \multicolumn{4}{|c|}{ Base SNIS - RS } \\
\hline & & PMG & & & & \multicolumn{2}{|c|}{ PMGIRS } & \multicolumn{2}{|c|}{ PIRS } \\
\hline & & Sim & Não & Sim & Não & Sim & Não & Sim & Não \\
\hline Araçatuba & 9 & 4 & 5 & 6 & 3 & 5 & 2 & 0 & 7 \\
\hline Araraquara & 8 & 4 & 4 & 5 & 3 & 4 & 3 & 1 & 6 \\
\hline Assis & 7 & 2 & 5 & 6 & 1 & 4 & 1 & 3 & 2 \\
\hline Bauru & 16 & 7 & 9 & 11 & 5 & 9 & 3 & 0 & 12 \\
\hline Campinas & 33 & 15 & 18 & 23 & 10 & 23 & 6 & 12 & 17 \\
\hline Itapetininga & 11 & 6 & 5 & 8 & 3 & 5 & 3 & 0 & 8 \\
\hline Litoral Sul Paulista & 7 & 2 & 5 & 4 & 3 & 4 & 2 & 1 & 5 \\
\hline Macro Metropolitana Paulista & 26 & 5 & 21 & 13 & 13 & 10 & 13 & 3 & 20 \\
\hline Marília & 5 & 1 & 4 & 3 & 2 & 4 & 1 & 0 & 5 \\
\hline Metropolitana de São Paulo & 42 & 17 & 25 & 24 & 18 & 28 & 9 & 9 & 28 \\
\hline Piracicaba & 14 & 7 & 7 & 9 & 5 & 10 & 2 & 3 & 9 \\
\hline Presidente Prudente & 13 & 7 & 6 & 10 & 3 & 10 & 2 & 3 & 9 \\
\hline Rubeirão Preto & 28 & 11 & 17 & 20 & 8 & 15 & 9 & 1 & 23 \\
\hline São José do Rio Preto & 13 & 4 & 9 & 10 & 3 & 9 & 2 & 1 & 10 \\
\hline Vale do Paraíba Paulista & 18 & 7 & 11 & 8 & 10 & 5 & 8 & 0 & 13 \\
\hline Total & 250 & 99 & 151 & 160 & 90 & 145 & 66 & 37 & 174 \\
\hline
\end{tabular}

Fonte: SINIS (BRASIL, 2018a), IBGE (2014), SNIS-RS (BRASIL, 2018b).

No SINIR, há dados apresentados, para a pesquisa "Perfil dos Municípios Brasileiros", dos quais 99, dos 250 municípios, possuem PMGIRS no ano de 2013 e, para a pesquisa do Ministério do Meio Ambiente (MMA), há 160 municípios com o indicativo de PMGIRS. Logo, observa-se uma melhoria da condição, visto que em 2013, existiam 151 e, em 2015, 90 municípios descumprindo o estabelecido na PNRS.

Ao se considerar os dados do SNIS-RS, dos 250 municípios, 211 responderam as informações quanto aos PMGIRS ou PIRS, sendo que 146 destacaram ter PMIGRS e 37 PIRS. Porém, destes, 30 indicam ter os dois tipos de Planos (PMGIRS e PIRS) e 7 municípios possuem apenas o PIRS.

Estudos Geográficos, Rio $\quad$ Claro, $\quad$ 16(2): 46-63, jul./dez. $2018 \quad$ (ISSN 1678 -698X) http://www.periodicos.rc.biblioteca.unesp.br/index.php/estgeo 
No Quadro 2 têm-se os 39 municípios que não responderam quanto a existência de PMGIRS ou PIRS. A não obtenção dessas informações, no SNIS-RS, indica o não cumprimento dos municípios quanto: ao compartilhamento das informações (BRASIL, 2011; 2010a); e à elaboração do Plano Municipal (BRASIL, 2010a; 2010b). Este não cumprimento prejudica a captação municipal de recursos na União.

\section{Quadro 3 - Municípios que não responderam quanto à existência do PMGIRS ou PIRS na base do SNIS-RS 2016}

\begin{tabular}{|c|c|}
\hline & Base SNIS-RS \\
\hline Mesorregião & Municípios que não responderam \\
\hline $\begin{array}{l}\text { Araçatuba } \\
\text { Araraquara } \\
\text { Assis } \\
\text { Bauru } \\
\text { Campinas } \\
\text { Itapetininga } \\
\text { Litoral Sul Paulista } \\
\text { Macro Metropolitana Paulista } \\
\text { Marília } \\
\text { Metropolitana de São Paulo } \\
\text { Piracicaba } \\
\text { Presidente Prudente } \\
\text { Ribeirão Preto } \\
\text { São José do Rio Preto } \\
\text { Vale do Paraíba Paulista }\end{array}$ & $\begin{array}{l}\text { Andradina, Valparaíso } \\
\text { Ibaté } \\
\text { Assis, Piraju } \\
\text { Agudos, Jaú, Pederneirass, Promissão } \\
\text { Paulínia, Itapira, Mococa, Vinhedo } \\
\text { Itapetininga, Laranjal Paulista, Taquarituba } \\
\text { Peruíbe } \\
\text { Cabreúva, Campo Limpo Paulista, São Roque } \\
\text { Biritiba Mirim, Carapicuíba, Cubatão, Embu-Guaçu, Mairiporã } \\
\text { São Pedro, Tietê } \\
\text { Adamantina } \\
\text { Barretos, Batatais, Taquaritinga, Guará } \\
\text { Jales, José Bonifácio } \\
\text { Cachoeira Pauista, Campos do Jordão, Cunha, São Sebastião, Ubatuba }\end{array}$ \\
\hline Total & 39 \\
\hline
\end{tabular}

Fonte: SNIS-RS (BRASIL, 2018b).

Quanto à coleta de dados em sites, há também a publicização dos Planos na Coordenadoria de Planejamento Ambiental, no Sistema Ambiental Paulista do governo do estado de São Paulo (São Paulo, 2018). Neste há 400 municípios com Planos divulgados, sendo que, destes, 174 têm a obrigatoriedade do Plano, atendendo aos 19 incisos (BRASIL, 2010a, art. 19). É importante considerar que esse Plano informado precisa ter a confirmação de sua instituição.

Para isso, existem duas formas claras para verificar essa publicização: no sítio da Prefeitura Municipal e/ou no sítio da Câmara Municipal. Porém verificaramse inúmeras dificuldades na coleta dos PMGIRS e/ou PIRS.

Observou-se que: a) os Planos e as Leis que os institui não estão alocados no mesmo sítio, o que dificulta inclusive identificar se os Planos divulgados foram os instituídos; b) por vezes foi encontrada a Lei que instituía o Plano, mas este último não estava público, assim como o contrário, Plano público, sem a Lei instituidora; c) especificamente no caso dos PIRS, alguns foram encontrados no site do Consórcio, mas não havia nenhuma sinalização do mesmo no site da Prefeitura, além de dificilmente estarem legalizados; d) alguns municípios elaboraram Políticas Municipais de Resíduos Sólidos, o que vem a ser algo relevante na construção regulatória municipal, porém, neste quesito, foram identificados alguns descompassos.

Primeiro deve-se destacar que a Política Municipal de Resíduos Sólidos é diferente de um Plano Municipal de Resíduos Sólidos. A Política abrange o conjunto de instrumentos norteadores da ação, tanto municipal, estadual, nacional e até do Distrito Federal (BRASIL, 2018b). Já o Plano "contempla a problemática dos

Estudos Geográficos, Rio Claro, 16(2): 46-63, jul./dez. $2018 \quad$ (ISSN 1678 -698X) http://www.periodicos.rc.biblioteca.unesp.br/index.php/estgeo 
diversos tipos de resíduos gerados, as alternativas de gestão e gerenciamento passíveis de implementação, planos de metas, programas, projetos e ações correspondentes", ou seja, propõe diretrizes, estratégias e metas (BRASIL, 2018c). Em segundo, a instituição de uma Política não significa, automaticamente, a instituição do Plano. Neste ínterim, foi diagnosticado um erro, que se supõe de interpretação, por parte dos municípios, pois alguns elaboraram Políticas Municipais de Resíduos Sólidos e as nomearam como PMGIRS, enquanto outros tinham um PMGIRS organizado separadamente e, para instituí-lo, utilizou a Lei de instituição da Política, ao invés de uma Lei específica para o PMGIRS. Neste quesito, subentendese que, se não está explicitada a averbação da legalização do Plano na referida Política, o devido PMGIRS não está formalizado, como alegado por alguns representantes via contato telefônico ou por e-mail.

Observou-se que parte dos municípios, para cumprir o exigido pela PNRS, incorporou o PMIGRS aos Planos Municipais de Saneamento Básico. Os Planos nestas condições e a conjuntura que os cercam não foram objeto de análise deste artigo.

Após essa busca dos Planos e Leis, fez-se contato direto com as Secretarias ou Departamentos responsáveis, a fim de obter informações sobre os PMGIRS dos municípios. Neste processo, houve percalços na busca pelo telefone da Prefeitura Municipal e da Secretaria (ou Departamento) responsável. Isto se deve pela falta de transparência dos próprios meios de comunicação, pois, por vezes, no sítio das Prefeituras Municipais não havia a informação do contato (telefone) dos setores responsáveis por resíduos sólidos. Além disso, observaram-se casos em que os contatos, quando encontrados, nem sempre estavam atualizados.

Constatou-se que, em determinados municípios, as Secretarias/Departamentos responsáveis não possuíam conhecimento da existência ou não do Plano. É importante considerar que, na maioria destes casos, apenas um único responsável (por vezes o próprio secretário) possuía a informação sobre os Planos. Esta última apuração trouxe lentidão ao já extenso trabalho de busca dos Planos, pois encontrar um único responsável direto entre as inúmeras repartições públicas mostrou-se contraproducente quanto à necessária publicidade de dados. Estes empecilhos geraram inúmeras ligações infrutíferas de um setor a outro e vários encaminhamentos de chamadas até identificar tanto a repartição responsável, quanto o próprio responsável.

$\mathrm{Na}$ Tabela 2 é apresentado um resumo das várias ligações para identificar o detentor das informações sobre os Planos. Em média foram feitas 3 ligações para cada um dos 250 municípios obrigados, segundo a PNRS, a elaborar o PMGIRS/PIRS. Ressalva-se que este número representa apenas as ligações, pois se desconsiderou os encaminhamentos de uma secretaria à outra, logo, esta média aumentaria.

Estudos Geográficos, $\quad$ Rio $\quad$ Claro, $\quad 16(2): \quad 46-63, \quad$ jul./dez. $2018 \quad$ (ISSN 1678 -698X) http://www.periodicos.rc.biblioteca.unesp.br/index.php/estgeo 


\section{Tabela 2 - Total, média de ligações, e-mail respondidos e PMGIRS/PIRS instituído nos municípios, por mesorregião do estado de São Paulo}

\begin{tabular}{l|r|r|r|r|r}
\hline Mesorregiões & $\begin{array}{c}\text { Municípios } \\
\text { (Número) }\end{array}$ & $\begin{array}{l}\text { Ligações } \\
\text { (Número) }\end{array}$ & $\begin{array}{c}\text { Ligações } \\
\text { por } \\
\text { Município } \\
\text { (Média) }\end{array}$ & $\begin{array}{c}\text { Municípios } \\
\text { respondentes } \\
\text { ao e-mail } \\
\text { (Número) }\end{array}$ & $\begin{array}{c}\text { PMGIRS/PIRS } \\
\text { instituído } \\
\text { (Número) }\end{array}$ \\
\hline Araçatuba & 9 & 37 & 4,1 & 3 & 5 \\
Araraquara & 8 & 35 & 4,4 & 1 & 2 \\
Assis & 7 & 39 & 5,6 & 1 & 5 \\
Bauru & 16 & 87 & 5,4 & 8 & 8 \\
Campinas & 33 & 114 & 3,5 & 8 & 8 \\
Itapetininga & 11 & 25 & 2,3 & 5 & 5 \\
Litoral Sul Paulista & 7 & 23 & 3,3 & 4 & 5 \\
Macro Metropolitana Paulista & 26 & 73 & 2,8 & 9 & 10 \\
Marília & 5 & 11 & 2,2 & 2 & 2 \\
Metropolitana de São Paulo & 42 & 100 & 2,4 & 7 & 24 \\
Piracicaba & 14 & 34 & 2,4 & 1 & 3 \\
Presidente Prudente & 13 & 36 & 2,8 & 4 & 10 \\
Rubeirão Preto & 28 & 64 & 2,3 & 8 & 14 \\
São José do Rio Preto & 13 & 37 & 2,8 & 5 & 3 \\
Vale do Paraíba Paulista & 18 & 31 & 1,7 & 69 & 111 \\
\hline Total & 250 & 746 & 3,0 & & 3 \\
\hline Fonte: Pesquisa de camp
\end{tabular}

Fonte: Pesquisa de campo.

O contato com o responsável sobre o manejo de resíduos sólidos favoreceu a constatação da situação do município quanto ao Plano, pois neste contato era solicitado o encaminhamento, por e-mail, do PMGIRS e/ou PIRS e da Lei que o instituía. Neste ínterim, vale a ressalva de que alguns e-mails repassados pelos responsáveis eram com endereço pessoal e não profissional, da Secretaria/Departamento do município, logo nem todos do setor ficavam cientes da pesquisa. Durante o contato, foi possível identificar se: havia PMGIRS ou PIRS; estavam instituídos; e estavam em processo de revisão; além de outros relatos.

$\mathrm{Da}$ pesquisa de campo, apenas 111 municípios, dos 250, apresentam PMGIRS/PIRS, com Lei instituindo-o (TABELA 2). É importante destacar que dos municípios considerados e com contato por e-mail viabilizado (201 municípios), 69 responderam ao e-mail. Outra constatação é que desses Planos encaminhados, alguns não estavam públicos e instituídos ou estavam em fase de revisão (que estava sendo elaborada, concluída ou apenas almejada). Por fim, a confirmação dos Planos e das Leis se apresentou dificultosa, principalmente, pela falta de atendimento dos municípios ao Estatuto da Cidade, à Lei de acesso à informação e aos desígnios da PNRS (BRASIL, 2011a; BRASIL, 2010a).

No contexto da cidade, inúmeros dispositivos normativos preveem a necessária participação popular, cujos pressupostos óbvios são a publicização e acesso às informações. Destacam-se os artigos 182 e 183 da Constituição Federal de 1988 (BRASIL, 1988) e seu regulamento legal, o Estatuto da Cidade que, ao disporem sobre a política urbana, visam ao pleno desenvolvimento das funções sociais da cidade e da propriedade urbana, prevendo como instrumento especial o plano diretor (BRASIL, 2001, art. 4ํㅡㄴ III, a), cuja elaboração e revisão deve seguir o disposto no art. 40, §4 (BRASIL, 2001). Notadamente nos processos de aprovação e revisão do Plano Diretor, o povo deve manifestar-se direta e espontaneamente, ao que o poder público deve mostrar-se sensível, receptivo e, mais, indutor e garante dessa participação efetiva, tudo a fim de que a política urbana espelhe os interesses

Estudos Geográficos, Rio Claro, 16(2): 46-63, jul./dez. $2018 \quad$ (ISSN $\quad$ 1678-698X) http://www.periodicos.rc.biblioteca.unesp.br/index.php/estgeo 
sociais, garantindo a gestão democrática da cidade, nos termos do art. 43 do Estatuto (BRASIL, 2001).

O determinado para os Planos Diretores no tocante à publicidade e ao acesso de qualquer interessado aos documentos e informações produzidos é extensível a todos os Planos Municipais, incluindo o de resíduos sólidos, por força do princípio democrático que informa o Estado brasileiro (BRASIL, 1988, art. 1ํㅜㅇ, parágrafo único). Apesar de determinado pela Constituição e pelas leis, os agentes públicos descumprem seu dever de publicização.

A falta de publicidade é agravada pela ausência de Planos Diretores em mais de $10 \%$ dos municípios obrigados a ter Plano Diretor (IBGE, 2015, p. 18) e a ausência de participação popular na elaboração e revisão de planos diretores que, quando existem, são elaborados por técnicos ou empresas contratadas, sem o componente democrático participativo (COLENCI; OLIVEIRA; OLIVEIRA, 2015, p.14).

Negando a publicização ou dificultando o acesso à informação fenece qualquer participação popular, pelo que as políticas públicas (como no caso de resíduos sólidos) seguem sem limitar a propriedade privada no âmbito urbano, como descrito por Marx e Engels (1993, p. 68): "o poder político do Estado moderno nada mais é do que um comitê (Ausschuss) para administrar os negócios comuns de toda a classe burguesa".

\section{CONCLUSÕES}

O controle das ações públicas através da sociedade, preconizada pelo Estatuto da Cidade como necessária à política urbana, favorecida pela Lei de acesso à informação (Lei no 12.527/2011) e pela Constituição Federal, além de documentos de órgãos internacionais (como a ONU e a OEA), legitima o regime democrático de direito da população brasileira.

Especificamente sobre o acesso aos dados sobre a gestão do manejo de resíduos sólidos, fora essas normas citadas, ainda regem o tema a PNRS e o Decreto no 7.404/2010. Estes estabelecem a obrigatoriedade dos municípios e do Distrito Federal elaborarem Planos (instrumentos da PNRS) que tornem públicos a realidade da questão dos resíduos sólidos no município, além de evidenciar, a título de controle social, as diretrizes, estratégias e metas com relação à problemática. Isto posto, os Planos devem ser confeccionados para livre acesso da população, abordando um conteúdo necessário para o conhecimento do tema por todos.

No SINIR, outro instrumento da PNRS, além do MUNIC/IBGE e do SNIS (todos estes são bases de dados governamentais sobre o tema), procurou-se identificar a facilidade de acesso e obtenção de dados públicos sobre resíduos sólidos. Constatou-se que nestas bases a informação não é encontrada de forma clara, objetiva, transparente e de simples linguagem, como estabelecido pela Lei de acesso à informação. Além disso, foi possível identificar que dos 250 municípios, com mais de 20.000 habitantes e que são obrigados a elaborar, instituir e divulgar tais Planos há aqueles que não os tem segundo essas bases, descumprido ao estabelecido pela PNRS. Acrescido a isto, há aqueles municípios que não indicaram, na base auto declaratória do SNIS, a existência ou não dos Planos, não publicizando a informação.

Utilizando-se do conceito da transparência ativa, aquela que estabelece como dever do município publicizar seus dados, percorre-se por 7 meses a pesquisa em busca dos PMGIRS e/ou PIRS dos municípios elegidos.

Estudos Geográficos, Rio $\quad$ Claro, $\quad$ 16(2): 46-63, jul./dez. $2018 \quad$ (ISSN 1678 -698X) http://www.periodicos.rc.biblioteca.unesp.br/index.php/estgeo 
Por fim, a partir da pesquisa de campo constata-se a: dificuldade de acesso ao link correto do Plano; falta de clareza quanto ao Plano ser realmente legalizado ou não; descrédito ou até mesmo desconsideração por parte de alguns responsáveis, nos municípios, em fornecer dados públicos através de e-mail institucional da Secretaria/Departamento que trata de resíduos sólidos; descumprimento das normas que regem sobre o acesso à informação quanto à correta identificação dos telefones, tanto da Prefeitura, quanto dos setores municipais; falta de conhecimento pelos próprios responsáveis e envolvidos na pasta sobre a real condição do Plano. Condição que prejudica o controle social proposto pela PNRS (BRASIL, 2010a) e que é garantido pela constituição Federal (BRASIL, 1988) e Lei no 12.527/2011 (BRASIL, 2011).

A pesquisa evidencia o hiato entre a publicidade "prometida" e a "entregue" efetivamente às pessoas, em franco descumprimento ao garantido pela legislação, denotando que a trama real das relações entre interesses (econômicos) e o Estado conduz a processos prático-políticos ainda bastante opacos.

\section{REFERÊNCIAS}

ARNSTEIN, S. R. Uma escada da participação cidadã. Revista da Associação Brasileira para o Fortalecimento da Participação - PARTICIPE, Porto Alegre/Santa Cruz do Sul, v. 2, n. 2, p. 4-13, jan. 2002. Disponível em: <http://aeessp.org.br/escada.pdf>. Acesso em: 10 out. 2017.

BRASIL. Lei no 6.938, de 31 de Agosto de 1981. Dispõe sobre a Política Nacional do Meio Ambiente, seus fins e mecanismos de formulação e aplicação, e dá outras providências. 1981. Diário Oficial da União. Brasília, DF. Seção 1 - 02/09/1981, Página 16509. Disponível em: <http://www2.camara.leg.br/legin/fed/lei/1980-1987/lei6938-31-agosto-1981-366135-publicacaooriginal-1-pl.html>. Acesso em: 15 mar. 2018.

. Constituição Federal de 1988. Constituição da República Federativa do Brasil. Promulgada em 5 de outubro de 1988. Disponível em <http://www.planalto.gov.br/ccivil 03/constituicao/constituição.htm>. Acesso em: 15 mar. 2018.

Lei $n^{\circ} 10.257$, de 10 de julho de 2001. Regulamenta os art. 182 e 183 da Constituição Federal, estabelece diretrizes gerais da política urbana e dá outras providências. Diário Oficial [da] República Federativa do Brasil, Brasília, DF, 11 jul. 2001. Disponível em: <http://www.planalto.gov.br/ccivil 03/leis/LEIS 2001/L10257.htm>. Acesso em: 11 dez. 2017.

Lei $n^{\circ}$ 12.305, de 2 de agosto de 2010. Institui a Política Nacional de Resíduos Sólidos; altera a Lei $n^{\circ}$ 9.605, de 12 de fevereiro de 1998; e dá outras providências. 2010a. Diário Oficial [da] República Federativa do Brasil, Brasília, DF. Disponível em: <http://www.planalto.gov.br/ccivil 03/ ato2007-2010/2010/lei/l12305.htm>. Acesso em: 15 fev. 2018.

- Decreto $n^{\circ}$. 7.404, de 23 de Dezembro de 2010. Regulamenta a Lei no 12.305, de 2 de agosto de 2010, que institui a Política Nacional de Resíduos Sólidos, cria o Comitê Interministerial da Política Nacional de Resíduos Sólidos e o Comitê Orientador para a Implantação dos Sistemas de Logística Reversa, e dá outras providências. 2010b. Diário Oficial [da] República Federativa do Brasil, Brasília,

Estudos Geográficos, Rio Claro, 16(2): 46-63, jul./dez. $2018 \quad$ (ISSN 1678 -698X) http://www.periodicos.rc.biblioteca.unesp.br/index.php/estgeo 
DF. Disponível em: <http://www.planalto.gov.br/ccivil 03/ ato20072010/2010/Decreto/D7404.htm >. Acesso em: 12 fev. 2018.

Lei $n^{\circ} 12.527$, de 18 de Novembro de 2011. Regula o acesso a informações previsto no inciso XXXIII do art. 5o, no inciso II do $\S 30$ do art. 37 e no $\S 20$ do art. 216 da Constituição Federal; altera a Lei no 8.112, de 11 de dezembro de 1990; revoga a Lei no 11.111, de 5 de maio de 2005, e dispositivos da Lei no 8.159, de 8 de janeiro de 1991; e dá outras providências. 2011a. Diário Oficial [da] República Federativa do Brasil, Brasília, DF. Disponível em: <http://www.planalto.gov.br/ccivil 03/ ato20112014/2011/lei/l12527.htm >. Acesso em: 12 fev 2018.

Controladoria-Geral da União. Acesso à Informação Pública: uma introdução à Lei 12.527, de 18 de novembro de 2011. 2011b. Disponível em: $<$ http://www.acessoainformacao.gov.br/central-de-conteudo/publicacoes/arquivos/cartilh aacessoainformacao.pdf>. Acesso em: 5 mar. 2018.

. Ministério do Meio Ambiente. Plano Nacional de Resíduos Sólidos. 2012. Disponível em: $<$ http://www.sinir.gov.br/documents/10180/12308/PNRS Revisao Decreto 280812.pdf/e183f0e75255-4544-b9fd-15fc779a3657>. Acesso em: 05 fev. 2018.

Ministério das Cidades. Secretaria Nacional de Saneamento Ambiental SNSA Sistema Nacional de Informações sobre Saneamento (SNIS): Diagnóstico do Manejo de Resíduos Sólidos Urbanos - 2016. Brasília: MCIDADES.SNSA, 2018b. Disponível em: <http://www.snis.gov.br/diagnostico-residuos-solidos/diagnostico-rs-2016>. Acesso em: 5 mar. 2018.

Sistema Nacional de Informações sobre a Gestão dos Resíduos Sólidos (SINIR). Planos Municipais de Gestão Integrada de Resíduos Sólidos. 2018a. Disponível em: $<$ http://sinir.gov.br/web/guest/2.5-planos-municipais-de-gestao-integrada-de-residuos-solidos $>$. Acesso: 03 abr. 2018.

. Ministério do Meio Ambiente. Cidades Sustentáveis. Resíduos Sólidos. Política Nacional de Resíduos Sólidos. 2018b. Disponível em: $<$ http://www.mma.gov.br/cidades-sustentaveis/residuos-solidos/politica-nacional-deresiduos-solidos>. Acesso em 25 abr. 2018.

Ministério do Meio Ambiente. Cidades Sustentáveis. Resíduos Sólidos. Instrumentos da Política de Resíduos. Plano Municipal de Gestão Integrada de Resíduos Sólidos. 2018c. Disponível em: <http://www.mma.gov.br/cidadessustentaveis/residuos-solidos/instrumentos-da-politica-de-residuos/planosmunicipais-de-gest\%C3\%A3o-integrada-de-res\%C3\%ADduos-s\%C3\%B3lidos >. Acesso em 25 abr. 2018.

COLENCI, P. L.; OLIVEIRA, C. M.; OLIVEIRA, F. P. Um diagnóstico da efetividade da contribuição cidadã na gestão pública municipal. Revista do Centro de estudos de Direito do Ordenamento, do Urbanismo e do Ambiente - CEDOUA, ํo ${ }^{36}$, ano XVIII, no 2, 2015, p. 9-25. Disponível em: $<$ http://www.uc.pt/fduc/cedoua/slideshow/capa36?hires\#Revista\%20n\%C2\%BA36>. Acesso em: 14 fev. 2018.

Estudos Geográficos, Rio Claro, 16(2): 46-63, jul./dez. $2018 \quad$ (ISSN $\quad$ 1678-698X) http://www.periodicos.rc.biblioteca.unesp.br/index.php/estgeo 
COSTA, E. R. Política Nacional de resíduos sólidos e sua regulamentação. Jusbrasil. Disponível em: <http://nardes.jusbrasil.com.br/noticias/252707908/politicanacional-de-residuos-solidos-e-sua-regulamentacao >. Acesso em: 20 fev. 2018.

CUNHA, A. G. da. Dicionário etimológico nova fronteira da língua portuguesa. 2. ed. Rio de Janeiro: Nova Fronteira, 2010.

IBGE. Instituto Brasileiro de Geografia e Estatística. Pesquisa de Informações Básicas Municipais - MUNIC. 2014. Disponível em: $<$ www.ibge.gov.br/home/estatistica/economia/perfilmunic/2013/>. Acesso em: 03 abr. 2018.

GONÇALVES, M. E.. Direito da Informação: novos direitos e formas de regulação na sociedade da informação. Almedina: Coimbra, 2003.

HOCH, P. A.; RIGUI, L. M.; SILVA, R. L. da. Desafios à concretização da transparência ativa na internet, à luz da lei de acesso à informação pública: análise dos portais dos Tribunais Regionais Federais. Revista Direitos Emergentes na Sociedade Global, v. 1, n. 2, p. 257-286, mar. 2013. Disponível em: $<$ https://periodicos.ufsm.br/REDESG/article/view/7303 >. Acesso em: 26 jun. 2018.

IBGE. Instituto Brasileiro de Geografia e Estatística. Sistema IBGE de Recuperação Automática - SIDRA. Censo Demográfico de 2010. Disponível em: $<$ https://sidra.ibge.gov.br/pesquisa/censo-demografico/demografico-2010/universocaracteristicas-da-populacao-e-dos-domicilios/>. Acesso em: 03 abr. 2018.

IBGE - Instituto Brasileiro de Geografia e Estatística. Pesquisa de Informações Básicas Municipais - MUNIC. 2015. Disponível em: $<$ https://biblioteca.ibge.gov.br/visualizacao/livros/liv95942.pdf>. Acesso em: 03 jun. 2018.

INTERNACIONAL CONFERENCE ON THE RIGHT PUBLIC INFORMATION. February, 27-29, 2008. Declaração de Atlanta e plano de ação para o avanço do direito de acesso à informação. Disponível em: $<$ http://www.cartercenter.org/resources/pdfs/peace/americas/atlanta declaration uno fficial portuguese.pdf $>$. Acesso em 26 jun. 2018

LUSTOSA, M. C. J.; YOUNG, C. E. F. Política Ambiental. In: KUPFER, D.; HASENCLEVER, L. (Orgs). Economia industrial: fundamentos teóricos e práticas no Brasil, 2. ed. Rio de Janeiro: Elsevier, 2013. cap. 26, p. 341-352.

MARX, K.; ENGELS, F. Manifesto do partido comunista. Rio de Janeiro: Vozes, 1993

OLIVEIRA, C. M. de; LOPES, D. M.; COLENCI, P. L.; SOUSA, I. C. N. Democracia Participativa no Direito Urbanístico. São Carlos: EdUFSCar, 2016.

OLIVEIRA, R. M. O novo sistema de acesso à informação e a influência do paradigma do Estado Democrático de Direito na superação da cultura do segredo. Jus Navigandi, Teresina, ano 18, n. 3666, 15 jul. 2013. Disponível em:

Estudos Geográficos, $\quad$ Rio $\quad$ Claro, $\quad$ 16(2): $\quad 46-63, \quad$ jul./dez. $2018 \quad$ (ISSN $\quad 1678-698 X)$ http://www.periodicos.rc.biblioteca.unesp.br/index.php/estgeo 
$<$ https://jus.com.br/artigos/24943/o-novo-sistema-de-acesso-a-informacao-e-ainfluencia-do-paradigma-do-estado-democratico-de-direito-na-superacao-da-culturado-segredo >. Acesso em: 5 mar. 2018.

ORGANIZAÇÃO DAS NAÇÕES UNIDAS (ONU). Declaração Universal dos Direitos Humanos $\quad$ - 1948.2009 .20 Disponível $<$ http://www.onu.org.br/img/2014/09/DUDH.pdf >. Acesso em: 10 mar. 2018.

ORGANIZAÇÃO DAS NAÇÕES UNIDAS (ONU). Convenção das Nações Unidas contra a corrupção - 2003. 2007. Disponível em: <https://www.unodc.org/documents/pobrazil//Topics corruption/Publicacoes/2007 UNCAC Port.pdf>. Acesso em: 10 mar. 2018.

ORGANIZAÇÃO DOS ESTADOS AMERICANOS (OEA). Declaração Interamericana de princípios de Liberdade e Expressão - 2000. 2000. Disponível em: $<$ https://www.cidh.oas.org/basicos/portugues/s.convencao.libertade.de.expressao.htm>. Acesso em: 10 mar. 2018.

ORGANIZAÇÃO DAS NAÇÕES UNIDAS (ONU). Pacto Internacional do Direitos Civis e Políticos - 1976. 1976. Disponível em: $<$ http://www.refugiados.net/cid virtual bkup/asilo2/2pidcp.html\#a19>. Acesso em: 10 mar. 2018.

SÃO PAULO. Coordenadoria de Planejamento Ambiental. Plano de Resíduos Sólidos. Disponível em: <http://www2.ambiente.sp.gov.br/cpla/residuos-solidos/planos-deresiduos-solidos/>. Acesso em: 09 mai. 2018.

STOEBERL, J.; NOVELLI, R.F. O garantismo e o acesso à informação. Justiça do Direito, v. 27, n. 1, jan./jul., p. 148-160, 2013.

VIEIRA, L.; CADER, R. A Política Ambiental na década de 2002-2012. In: SADER, E. (Org.). 10 anos de governos pós-neoliberais no Brasil: Lula e Dilma. 1. ed. São Paulo, SP: Boitempo; Rio de Janeiro: FLACSO Brasil, 2013. p. 225-238.

Artigo submetido em: 03/08/2018 Aceito para publicação em: 04/11/2018 Publicado em: 14/12/2018 